\title{
Avaliação da aplicação da Resolução CONAMA 04/94 na definição dos estágios sucessionais de fragmentos florestais da Floresta Ombrófila Densa de Santa Catarina
}

\author{
Fernando Andreacci * \\ Rosemeri Carvalho Marenzi \\ Universidade do Vale do Itajaí, Campus Itajaí, Centro, CEP 88302-901, Itajaí - SC, Brasil \\ * Autor para correspondência \\ fandreacci@gmail.com
}

Submetido em 21/06/2017

Aceito para publicação em 06/09/2017

\section{Resumo}

Na Mata Atlântica, a conversão de áreas florestadas em outro tipo de uso do solo fica condicionada, entre outros, à classificação do estágio sucessional da floresta, sendo que diferentes estágios refletem em diferentes tamanhos e possibilidades de uso. Os parâmetros empregados na definição dos estágios sucessionais deste Bioma encontram-se descritos em resoluções específicas para cada estado, sendo que a resolução CONAMA 04/94 é própria para as florestas de Santa Catarina. Este estudo objetivou avaliar a aplicação dos critérios quantitativos da Resolução CONAMA 04/94 na definição dos estágios sucessionais da Floresta Ombrófila Densa, tendo como estudo de caso os fragmentos florestais da planície Norte do estado de Santa Catarina. Ao todo foram avaliados seis fragmentos localizados em diferentes unidades pedológicas, sendo avaliados o DAP e a altura média dos indivíduos, além da área basal e espécies indicadoras. Os resultados demonstram que a CONAMA 04/94 ignora características fitofisionômicas particulares das planícies arenosas do norte do estado. Também é demonstrada a incoerência do texto da CONAMA 04/94 na definição dos parâmetros estruturais e espécies indicadoras. Os resultados sugerem a necessidade urgente de revisão do texto da Resolução CONAMA 04/94, uma vez que os fragmentos florestais do estado podem estar sendo sujeitos a usos de solo incompatíveis com os definidos nas políticas públicas.

Palavras-chave: Estágios sucessionais; Licenciamento Ambiental; Mata Atlântica

\section{Abstract}

Evaluating the CONAMA 04/94 resolution to classify successional stages of rainforest fragments in Santa Catarina State. In the Atlantic Forest, land use and land-use change are partly determined based on a classification of the successional stages of forests. Different regeneration stages are limited to different amounts and types of use. The parameters used to define the successional stages of forests are described in specific resolutions for each of the states. CONAMA 04/94 is the resolution for the forests of Santa Catarina. The aim of this study was to evaluate the quantitative parameters in CONAMA 04/94 for classifying successional stages of forests in the northern coastal plains of the state. Six forest fragments with different soil types were evaluated using average DBH and average height of individuals, as well as basal area and indicator species. The results show that CONAMA 04/94 disregards certain phytophysiognomic characteristics of the northern coastal plains 
of the state. They also show that the CONAMA 04/94 text is incoherent regarding structural parameters and indicator species. The results suggest the urgent need to review the CONAMA 04/94 resolution because forest fragments could qualify for incorrect land uses according to what is defined in the current policy.

Key words: Atlantic Forest; Environmental licensing; Successional stages

\section{Introdução}

O Bioma da MataAtlântica é definido como um complexo de ecossistemas de importância ecológica e social. Originalmente distribuído em áreas de 17 estados brasileiros (e.g.: PI, CE, RN, PE, PB, SE, AL, BA, ES, MG, GO, RJ, MS, SP, PR, SC e $\mathrm{RS}$ ) e com uma superfície correspondente a $15 \%$ do território nacional, essa área de "riqueza fácil" subsidiou grande parte do desenvolvimento do país em troca de sua destruição. Iniciando pela exploração do pau-brasil, além de outras espécies madeiráveis de valor comercial, passando pelos ciclos do ouro, da cana-de-açúcar, do café, do cacau, da pecuária e, por fim, pelo processo de industrialização, com consequente urbanização, tendo as principais cidades e metrópoles brasileiras sido assentadas na área originalmente ocupada pela floresta (DEAN, 1996). Durante esses ciclos de destruição da Mata Atlântica, também tiveram origem as normas de proteção madeireira, florestal e ambiental no Brasil.

As normas de proteção oriundas do período colonial tinham preocupações eminentemente econômicas, de maneira a proteger as riquezas brasileiras que supriam Portugal (WAINER, 1993), enquanto no período imperial, nas leis que tratavam do assunto, havia uma preocupação com meio ambiente, ainda que de forma rudimentar (MEIRA, 2008). No período republicano, conforme exposto por Gaio (2014), importantes documentos concernentes à proteção do meio ambiente foram promulgados, tendo como expoente a Constituição Federal de 1988, que dedicou um capítulo específico ao tema. Nesse documento, a Mata Atlântica foi erigida ao status de patrimônio nacional e exigiu do poder público legislação que a tutelasse de modo específico, denotando que esta se trata de uma riqueza de toda a nação e que deve ser utilizada de forma racional e sustentável (SILVA, 1999).
Após uma lacuna de vários anos, foi promulgado o Decreto Federal 750/93, que revogou o muito criticado Decreto Federal 99.547/90, no qual, entre outros, foi reconhecida a existência de diferentes estágios de regeneração do Bioma Mata Atlântica, bem como foi exigido do Conselho Nacional do Meio Ambiente - CONAMA o estabelecimento da definição desses estágios de regeneração. Ainda em 1993, o CONAMA editou a Resolução no 10 (CONAMA, 1993) que, além de outras cosias, estabeleceu de maneira muito simples os parâmetros básicos para análise dos estágios de sucessão da Mata Atlântica e ecossistemas associados. Devido ao nítido gradiente de tipos de ecossistemas relacionados ao mesoclima, presentes na área de abrangência desse Bioma, o CONAMA editou de forma complementar resoluções específicas para cada estado, sendo que a Resolução no 02/94 e 04/94 (CONAMA, 1994a; 1994b) definiram a vegetação primária e secundária nos estágios inicial, médio e avançado para os estados do Paraná e de Santa Catarina, respectivamente.

O Decreto 750/93 foi revogado com a promulgação da Lei da Mata Atlântica em 2006 e posterior regulação (Decreto Federal 6.660/2008), porém não houve alterações significativas quanto aos regimentos sobre os estágios de regeneração do Bioma, sendo que o texto da CONAMA 10/1993 foi incorporado na Lei da Mata Atlântica. Ainda, de maneira a cumprir a exigência imposta pela Lei da Mata Atlântica, da definição de vegetação primária e de vegetação secundária nos estágios avançado, médio e inicial de regeneração do Bioma Mata Atlântica, o CONAMA em 2007 por meio da Resolução CONAMA 388 (CONAMA, 2007) convalidou as outras resoluções já promulgadas que tratavam do tema, entre elas a Resolução CONAMA 04/04.

Apesar do avanço legal, alguns fatores, tais como a falta de normatização para a amostragem da vegetação no texto da Resolução 04/04 e a falta de 
um estudo aprofundado sobre o processo de sucessão florestal, têm demonstrado a fragilidade da Resolução 04/94 (SIMINSKI; FANTINI, 2004). Embora o Decreto Federal 6.660/2008 tenha possibilitado liberdade metodológica para determinar o estágio sucessional da vegetação, desde que garantida a suficiência amostral e observados os parâmetros estabelecidos na Lei da Mata Atlântica, a falta de uma normatização padronizada da amostragem compromete os valores limites das variáveis estabelecidas pela resolução para diferenciar os estágios de regeneração (SIMINSKI; FANTINI, 2004; SIMINISK et al., 2013).

Inserida no contexto do Bioma da Mata Atlântica, encontra-se a Floresta Ombrófila Densa, tipo fitoecológico, que em Santa Catarina cobre o relevo desde as planícies até os mais altos morros, montanhas e encostas das Serras do Mar e Geral voltados para o oceano Atlântico (SEVEGNANI et al., 2013). Essa floresta, devido à sua enorme riqueza e diversidade de ambientes, é subdividida em diferentes formações de acordo com variações altitudinais e a fisionomia da vegetação. Para essa floresta, os trabalhos de (SIMINSKI et al., 2011; 2013; SIMINSKI; FANTINI, 2004) demonstram que existe grande dificuldade em classificar a vegetação estudada em apenas um dos estágios de regeneração definidos pela CONAMA 04 (1994b), principalmente se levado em consideração o diâmetro médio (DAP) e a área basal do fragmento estudado. Outro aspecto da determinação dos estágios sucessionais descrito na Resolução CONAMA 04/94 (1994b) está relacionado com a presença de espécies indicadoras para cada estágio. Conforme corroborado por demais autores (VELOSO et al., 1991; RODERJAN et al., 2002; BLUM; RODERJAN, 2007), diferentes patamares altitudinais implicam em diferenças florísticas relevantes para cada uma das subformações da floresta ombrófila densa, não sendo, portanto, uniforme o padrão de espécies indicadoras. Além disso, variações edáficas do ambiente promovem diferenças na estrutura e composição de florestas maduras e secundárias, refletindo em diferentes espécies indicadoras para ambientes muito próximos (VELOSO; KLEIN, 1961; CLARK et al., 1999; FINEGAN; DELGADO, 2000; RODERJAN et al., 2002). Por fim, em florestas secundárias as espécies que são socialmente mais importantes na estrutura da comunidade permeiam diferentes estágios sucessionais (SIMINSKI et al., 2011), dificultando a definição de espécies indicadoras de determinado estágio.

Além de parâmetros quantitativos (área basal, DAP médio, altura média) e espécies indicadoras, a CONAMA 04 apresenta outros parâmetros qualitativos que devem ser utilizados conjuntamente na definição do estágio sucessional das florestas. Esses parâmetros que versam sobre as características da comunidade epifítica e das trepadeiras, da serapilheira e do sub-bosque da floresta são subjetivos e sua definição está intimamente associada à experiência do técnico (JASTER, 2002), pois carecem de índices nas normativas (SPERZEL, 2016). Dessa maneira, uma melhor avaliação desses parâmetros requer comparações com outros fragmentos em situações semelhantes, o que difere da maior parte das análises utilizadas nos processos de licenciamento ambiental, que são realizadas pontualmente (PAZ, 2016).

A correta classificação dos estágios sucessionais das florestas da Mata Atlântica tem implicações diretas nas possibilidades de uso da terra (Lei 11.428/2006) e, consequentemente, na economia regional. Aliado a isso e com base no exposto, considerando a potencial fragilidade do texto da Resolução CONAMA 04/94 (1994b), pode-se inferir que tanto os profissionais responsáveis pela elaboração de inventários florestais utilizados no processo de licenciamento ambiental quanto o próprio meio ambiente estejam sofrendo em decorrência dessa fragilidade. Pelo primeiro aspecto pode ocorrer a incapacidade do técnico em aliar o instrumento legal com o observado em campo. Pelo segundo e também em decorrência do primeiro entendese que há possibilidade de que os fragmentos florestais estejam sendo classificados incorretamente durante o processo do licenciamento ambiental, perdendo-se o sentido e a finalidade de tal classificação.

Nesse contexto, este trabalho teve por objetivo avaliar a aplicação dos critérios quantitativos (área basal, DAP médio, altura média), além das espécies indicadoras, definidos na Resolução CONAMA 04/94 (1994b) em diferentes fragmentos da Floresta Ombrófila Densa na porção das Terras Baixas, utilizando como metodologia de levantamento de dados as diretrizes mínimas descritas na Instrução Normativa FATMA no 24 . 


\section{Material e Métodos}

A área de estudo localiza-se na planície costeira norte do estado de Santa Catarina, conforme setorização proposta por Horn-Filho (2003) (Figura 1). Geologicamente a área é bastante diversificada, compreendendo áreas de embasamento formada por rochas que constituem o seguimento setentrional do Escudo Catarinense, áreas de sistema deposicional continental (coluvial, leque aluvial e aluvial) e áreas de sistema deposicional transicional do período pleistocênicas, com destaque para os depósitos eólicos do pleistoceno superior, além de depósitos holocênicos de menores dimensões (HORN-FILHO et al., 2014). A geologia regional, aliada a outros fatores como clima, tempo, topografia e organismos, proporcionou também a gênese de tipos distintos de solos em áreas bastante próximas (Tabela 1).
Para realização deste estudo, foram selecionados seis fragmentos de florestas que, apesar de bastante próximos, encontram-se ou em áreas planas ou em pequenos morros, ocupando, portanto, diferentes unidades pedológicas e cotas altitudinais (Tabela 1). Neste trabalho, o enquadramento legal da vegetação das áreas de estudo seguiu o disposto em IBGE (2012). Sendo assim, as áreas foram classificadas como pertencentes ao domínio da Floresta Ombrófila Densa, mais especificamente na formação situada em terrenos sedimentares do terciário/quaternário, planícies e depressões aplanadas não suscetíveis a inundações que se iniciam na altitude de 5 até $30 \mathrm{~m}$ de altitude (Terras Baixas), além de uma área inserida muito próximo da encosta propriamente dita, cujas cotas altitudinais superam os $30 \mathrm{~m}$ (Submontana).

FIGURA 1: Localização geral da área de estudo e áreas de amostragem.

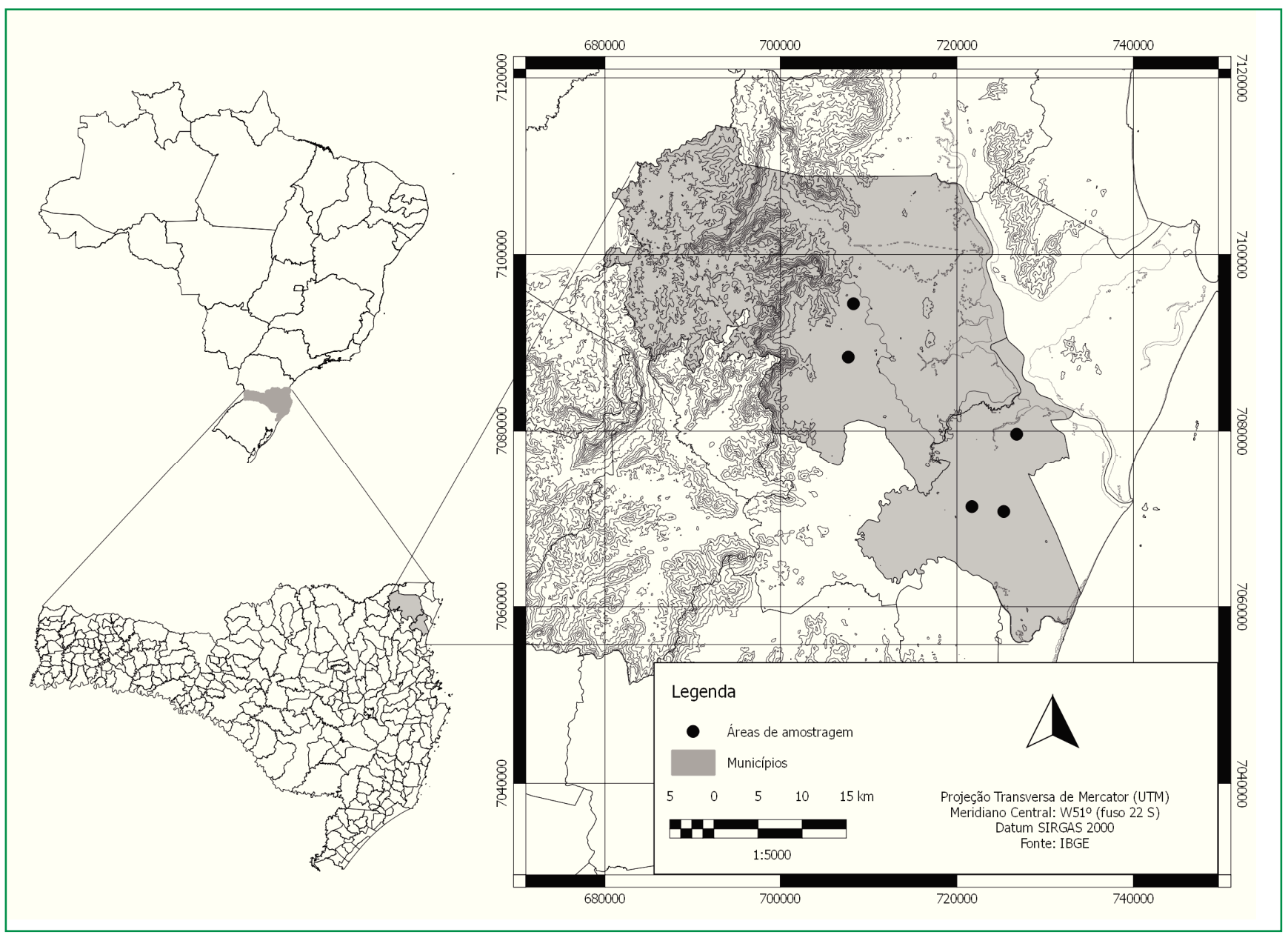


TABELA 1: Características das áreas amostradas. Formação corresponde à subdivisão da Floresta Ombrófila Densa conforme IBGE (2012): TB, Terras Baixas; SB, Submontana.

\begin{tabular}{cccc}
\hline Áreas & Unidade pedológica & Altitude média & Formação \\
\hline 1 & Cambissolo h plico* & $18 \mathrm{~m}$ & TB \\
2 & Neossolos quartzarênicos* & $12 \mathrm{~m}$ & $\mathrm{~TB}$ \\
3 & Argissolo vermelho-amarelo* & $20 \mathrm{~m}$ & $\mathrm{~TB}$ \\
4 & Neossolo quartzarênicos* & $11 \mathrm{~m}$ & $\mathrm{~TB}$ \\
5 & Argissolo vermelho-amarelo* & $50 \mathrm{~m}$ & $\mathrm{SB}$ \\
6 & Neossolos quartzarênicos* & $12 \mathrm{~m}$ & $\mathrm{~TB}$ \\
\hline
\end{tabular}

* EPAGRI (2002).

O clima da região é mesotérmico, sem estação seca definida e com verões quentes, do tipo Cfa conforme a classificação de Koeppen (PANDOLFO et al., 2002).

O método de amostragem da vegetação procurou atender as diretrizes mínimas de acordo a Instrução Normativa FATMA no 24 , que orienta os processos de licenciamento ambiental associadas à supressão de vegetação dentro do perímetro urbano no estado. Para isto, foi utilizado o método de amostragem aleatória simples, com unidades amostrais do tipo área fixa (parcelas) (MUELLER-DOMBOIS; ELLENBERG, 2003) com área mínima de $100 \mathrm{~m}^{2}$ dispostas aleatoriamente na área de abrangência da vegetação de cada fragmento. A escolha desse método também se deu em decorrência de este ser o mais comumente utilizado nos processos de licenciamento ambiental do estado (SIMINSKI; FANTINI, 2010), sendo, portanto, uma maneira de reproduzir resultados semelhantes aos que são apresentados nos órgãos ambientais.

Em cada parcela foram mensurados os diâmetros à altura do peito (DAP), estimadas as alturas de todos os indivíduos com DAP superior ou igual $4 \mathrm{~cm}$ e registrada a respectiva identidade taxonômica. A identificação taxonômica foi realizada a campo e, quando não foi possível, se deu por meio de chaves de identificação, literatura específica (BARROSO, 1986; MARCHIORI, 2000; 2007; SOBRAL, 2003; SOUZA; LORENZI, 2005) e Enciclopédia Flora Ilustrada Catarinense - FIC, além da comparação com a coleção do herbário virtual Reflora (2016). Para cada área de amostragem, foi calculada a média aritmética do DAP (diâmetro à altura do peito) e da altura total; e estimada a dominância e densidade do fragmento. $\mathrm{O}$ número de parcelas amostradas em cada área foi relativo a atingir a suficiência amostral para o DAP e altura total, bem como as estimativas de dominância com margem de erro máxima de $20 \%$ com $95 \%$ de probabilidade. A suficiência florística não foi avaliada, uma vez que não é um requisito nos processos de licenciamento ambiental de empreendimentos não causadores de significativo impacto ambiental no estado de Santa Catarina.

A dissimilaridade de abundância de espécies entre as áreas foi comparada por meio do índice de MorisitaHorn. Esse índice é altamente sensível às espécies mais abundantes (WOLDA, 1983), sendo adequado quando utilizado em situações em que a amostragem florística é insuficiente, uma vez que as espécies abundantes sempre estarão presentes nas amostras (CHAO et al., 2006).

Espécies dominantes foram definidas de acordo com Finegan (1996), sendo aquelas cuja soma dos valores de importância em ordem decrescente para uma determinada área perfazem o valor de 50\% do total.

Neste trabalho, para facilitar a discussão do texto, a Floresta Ombrófila Densa das Terras Baixas (VELOSO et al., 1991) é chamada de floresta de planície, suas demais formações (Sub Montana e Montana) são chamadas de floresta de encosta e as formações pioneiras de influência marinha são chamadas de restinga. A Resolução CONAMA 04/94 (1994b) é chamada de CONAMA-SC, enquanto a Resolução CONAMA 02/92 é chamada de CONAMA-PR. 


\section{Resultados}

A Tabela 2 apresenta as características estruturais das áreas estudadas. Para todas as áreas, foi alcançada a suficiência amostral, na qual o erro relativo da média ficou abaixo do limite estabelecido pela Instrução Normativa FATMA n- 24, sendo, portanto, as amostragens válidas para estudos com fins de licenciamento ambiental no estado.

As áreas 1, 2, 3, 5 e 6 apresentaram DAP médio inferior a $15 \mathrm{~cm}$, representando uma estrutura de floresta secundária em estágio médio de regeneração de acordo com a Resolução CONAMA-SC. As alturas médias, inferior a $12 \mathrm{~m}$ em todos os fragmentos, também indicam a estrutura secundária em estágio médio de regeneração.
Por outro lado, todas as áreas apresentaram rea basal superior a $20 \mathrm{~m}^{2} \mathrm{ha}^{-1}$, sendo indicativo de florestas primárias de acordo com a mesma resolução (ou floresta clímax, conforme interpretação que possa ser dada à intenção dessa resolução).

As variáveis que mais contribuíram na definição das espécies dominantes nas diferentes áreas estudadas foram a dominância e a densidade relativa (Tabela 3 ). Nas reas cobertas por Argissolos, a variável densidade relativa foi a que mais contribuiu, enquanto nas demais a contribuição maior partiu da dominância. Em geral, a frequência relativa foi a variável que menos contribuiu para todas as áreas.

Foi observada a preferência de determinadas espécies por tipo de solo específico. As áreas 3 e 5,

TABELA 2: Descrição das variáveis estruturais para todas as áreas amostradas. UA, unidades amostrais (parcelas); AA, área total amostrada (ha); DAP, diâmetro à altura do peito $(\mathrm{cm})$; HT, altura média $(\mathrm{m})$; DoA, dominância absoluta $\left(\mathrm{m}^{2} \mathrm{ha}^{-1}\right)$; DA, densidade absoluta (indivíduos ha- $\left.{ }^{-1}\right)$.

\begin{tabular}{ccccccc}
\hline Áreas & UA & AA & DAP (médio) & HT & DoA & DA \\
\hline 1 & 10 & 0,4 & $14,48 \pm 4,65$ & $10,24 \pm 0,4$ & $24,02 \pm 4,65$ & $1.155,00 \pm 160,437$ \\
2 & 27 & 0,54 & $12,80 \pm 4,65$ & $8,67 \pm 0,29$ & $21,21 \pm 3,45$ & $1.360,714 \pm 153,285$ \\
3 & 04 & 0,16 & $12,42 \pm 4,65$ & $9,94 \pm 0,46$ & $27,27 \pm 2,28$ & $1.750,00 \pm 199,811$ \\
4 & 06 & 0,24 & $15,51 \pm 4,65$ & $11,14 \pm 0,38$ & $33,60 \pm 2,92$ & $1.691,667 \pm 330,041$ \\
5 & 08 & 0,08 & $10,26 \pm 4,65$ & $9,04 \pm 0,44$ & $32,98 \pm 5,55$ & $3075,00 \pm 513,426$ \\
6 & 09 & 0,36 & $13,35 \pm 4,65$ & $9,06 \pm 0,23$ & $27,83 \pm 3,63$ & $1.888,889 \pm 288,142$ \\
\hline
\end{tabular}

TABELA 3: Parâmetros fitossociológicos das espécies dominantes nas diferentes áreas de estudo. FR, Frequência relativa; DR, densidade relativa; Dor, dominância relativa.

\begin{tabular}{|c|c|c|c|c|}
\hline $\begin{array}{l}\text { Áreas de } \\
\text { estudo }\end{array}$ & FR & DR & DoR & Espécies dominantes \\
\hline 1 & 39,13 & 56,5 & 71,06 & $\begin{array}{l}\text { Jacaranda puberula, Nectandra oppositifolia, Syagrus romanzoffiana, Alchornea } \\
\text { triplinervia, Tibouchina pulchra, Pera glabrata, A. glandulosa, Campomanesia } \\
\text { reitziana, Guarea macrophylla }\end{array}$ \\
\hline 2 & 42,04 & 57,2 & 64,36 & $\begin{array}{l}\text { Richeria grandis, Tapirira guianensis, Euterpe edulis, Ocotea pulchella, } \\
\text { Myrtaceae sp.1, Syagrus romanzoffiana, A. triplinervia, Calophyllum brasiliense }\end{array}$ \\
\hline 3 & 48,73 & 89,3 & 80,18 & $\begin{array}{l}\text { E. edulis, Miconia cinnamomifolia, P. glabrata, T. pulchra, Abarema langsdorffi, } \\
\text { S. romanzoffiana, N. oppositifolia, Schefflera morototoni, Cupania oblongifolia, T. } \\
\text { guianensis, ni.1, Casearia sylvestris }\end{array}$ \\
\hline 4 & 24,00 & 64,04 & 71,35 & O. pulchella, $R$. grandis, $P$. cattleianum \\
\hline 5 & 35,23 & 61,79 & 55,62 & $\begin{array}{l}\text { P. glabrata, Miconia cabucu, E. edulis, Hieronyma alchorneoides, J. puberula, } N \text {. } \\
\text { oppositifolia }\end{array}$ \\
\hline 6 & 30,02 & 60,59 & 72,75 & R. grandis, O. pulchella, T. guianensis, P. glabrata, T. pulchra, J. puberula \\
\hline
\end{tabular}


ambas Argissolos, compartilharam a dominância de Euterpe edulis Mart. e Nectandra oppositofilia Nees \& Mart., enquanto as áreas 2, 4 e 6, ambas com Neossolos, compartilharam Richeria grandis Vahl e Ocotea pulchella (Nees \& Mart.) Mez. As espécies Jacaranda puberula Cham., Pera glabrata (Schott) Poepp. ex Baill., Tibouchina pulchra (Cham.) Cogn. e Syagrus romanzoffiana (Cham.) Glassman $\mathrm{n}$ o demonstraram preferência por tipo de solo, sendo dominantes em ambos.

A análise de dissimilaridade de abundância das espécies entre as áreas, assim como revelado nas espécies dominantes (Tabela 3), demonstrou que existe um padrão de seleção das espécies por tipo de solo (Figura 2). As áreas de Argissolo e Cambissolo formaram um grupo, aqui chamado de áreas de menor drenagem, enquanto as áreas de Neossolo formaram outro grupo, chamados aqui de áreas de maior drenagem.

\section{Discussão}

Para fins de discussão, a Tabela 4 apresenta os valores de DAP médio e área basal de diferentes propostas de classificação dos estágios sucessionais da Mata Atlântica.

FIGURA 2: Diagrama de dissimilaridade de Morisita-Horn para as áreas de estudo.

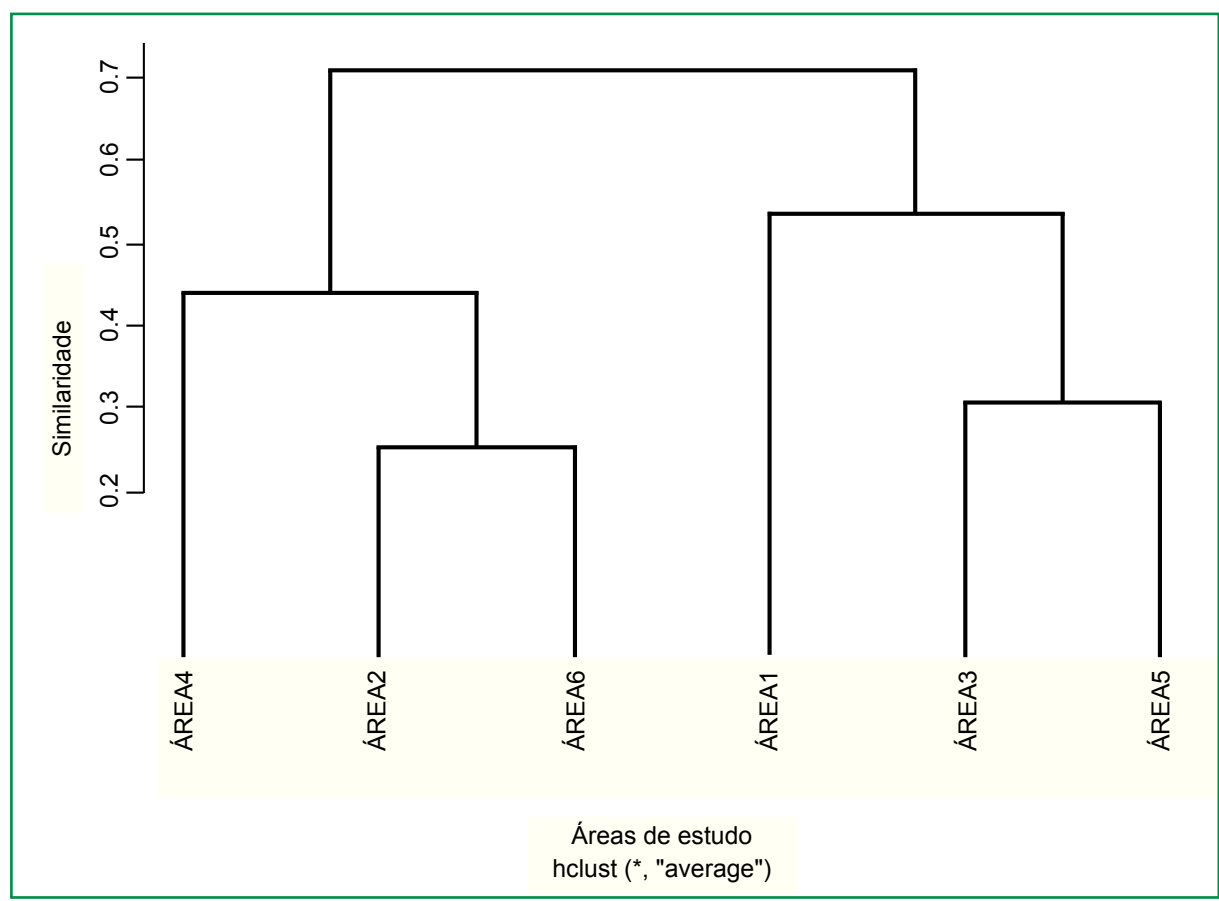

TABELA 4: Valores de DAP médio e área basal descritos em diferentes propostas de classificação de estágios sucessionais da Floresta Ombrófila Densa.

\begin{tabular}{ccccc}
\hline Propostas de classificação & $\begin{array}{c}\text { Estágios de } \\
\text { regeneração }\end{array}$ & DAP médio (cm) & Altura média (m) & Área basal ha-1 $^{-1}$ \\
\hline \multirow{2}{*}{ CONAMA-SC (04/94) } & Médio & até 15 & até 12 & até 15 \\
& Avançado & até 25 & até 20 & até 20 \\
CONAMA-PR (02/94) & Médio & 25 & 8 a 17 & $15-35$ \\
& Avançado & 40 & $>15$ & $>30$ \\
SIMININSK et al. (2013) & Médio & $10-15$ & 6 a 10 & $15-30$ \\
& Avançado & $\geq 15$ & $\geq 10$ & $\geq 30$ \\
\hline
\end{tabular}

* Não foram incluídos valores das propostas para o estágio inicial de regeneração, pois claramente os fragmentos analisados neste estudo não pertencem a essa classe. 
Os valores de área basal obtidos em todos os fragmentos analisados indicam o estágio sucessional avançado de acordo com o texto da Resolução CONAMA-SC. Por outro lado, os valores das demais variáveis (DAP médio e altura média) indicam o estágio médio de regeneração. Outros autores (SIMINSKI; FANTINI, 2004; SIMINSKI et al., 2013; RUSCHEL et al., 2009) observaram essa mesma tendência analisando áreas de diferentes idades de regeneração no estado de Santa Catarina, sendo que o trabalho de Siminski et al., (2013) culminou em uma nova proposta de classificação dos estágios sucessionais para o estado (Tabela 4). Essa nova proposta, bem como a Resolução CONAMA-PR, indica valores de área basais muito superiores àqueles descritos na CONAMA-SC. Apesar de a CONAMA-PR tratar da classificação da vegetação do estado vizinho, é de conhecimento que a estrutura das florestas da planície costeira norte de Santa Cataria e do sul do Paraná são muito semelhantes (MARQUES et al., 2010). Se fosse considerado como parâmetro de classificação, o texto da Resolução CONAMA-PR, ou a proposta de Siminski et al. (2013), todos os fragmentos analisados neste estudo poderiam ser classificados em estágio médio de regeneração com base nos parâmetros DAP médio, área basal e/ou altura média. Valores de área basal que facilmente ultrapassam àqueles descritos na Resolução CONAMA-SC, até mesmo se considerado o estágio avançado, são encontrados em florestas jovens com até 25 anos de regeneração (TABARELLI; MANTOVANI, 1999; LIEBSCH et al., 2007; RUSCHEL et al., 2009; SIMINSKI et al., 2013) e em florestas com DAP médio inferior ao descrito para o estágio médio da mesma resolução (SIMINSKI; FANTINI, 2004).

Uma consideração importante deve ser feita com relação ao critério de inclusão dos diâmetros dos indivíduos amostrados, uma vez que todas as variáveis analisadas sofrem alteração, de pequena a grande amplitude, em seus valores em função do DAP mínimo utilizado (SIMINSKI; FANTINI, 2004). Os estudos de Tabarelli e Mantovani (1999), Liebsch et al. (2007), Ruschel et al. (2009), Siminski e Fantini (2004) e Siminski et al. (2013) apresentam como critério de amostragem o diâmetro mínimo superior a $5 \mathrm{~cm}$. Se um critério de inclusão semelhante ao dos estudos citados tivesse sido utilizado no presente trabalho, um menor número de indivíduos teria sido amostrado, com consequente redução dos valores de área basal ha-1 $\mathrm{O}$ inverso ocorreria se nos trabalhos citados um menor diâmetro mínimo tivesse sido utilizado como critério de inclusão, sendo que a área basal estimada desses estudos seria superior àquela apresentada em função de um maior número de indivíduos amostrados. A partir do exposto, pode-se entender que, devido à diferença do critério de inclus o do diâmetro mínimo, os valores de área basal deste estudo n o poderiam ser comparados com os dos trabalhos citados. Contudo, conforme demonstrado por Siminski e Fantini (2004), não há variação significativa na área basal entre os diferentes critérios de inclusão dos diâmetros mínimos entre $3 \mathrm{e} 5 \mathrm{~cm}$, tornando válida a comparação. Por outro lado, o mesmo trabalho indica que para a variável DAP há diferença significativa na média quando utilizados os critérios de inclusão de 3 e $5 \mathrm{~cm}$, sendo que quanto maior o critério de inclusão, maior será o diâmetro médio obtido. Sendo assim, se fosse adotado o critério de inclusão do presente estudo nos trabalhos de Siminski e Fantini (2004), Siminski et al. (2013) e Ruschel et al. (2009), entende-se que o DAP médio seria ainda inferior ao apresentado pelos autores, enquanto a área basal não apresentaria diferença significativa. Portanto, conforme observado no presente estudo e na literatura citada, fica evidente a falta de coerência entre os parâmetros DAP (médio) e a área basal estabelecidos pela Resolução CONAMA-SC. Apesar de a Resolução CONAMA-PR e a proposta de Siminski et al. (2013) serem mais coerentes do ponto de vista da dendrometria, elas s o menos restritivas se comparada com a CONAMA-SC, permitindo a classificação de fragmentos florestais em estágios sucessionais inferiores.

Com relação à composição florística das áreas de estudo, percebe-se que um pequeno número de espécies é socialmente mais importante na estrutura da comunidade arbórea (Tabela 3). Esse aspecto é característico das florestas de planície da região Norte de Santa Catarina, onde as condições edáficas próprias refletem na estrutura e composição das espécies, contrastando com a pujança da vegetação ao longo das encostas da Serra do Mar e Serra Geral (VELOSO; KLEIN, 1961).

A dissimilaridade entre as áreas pelo método de Morisita-Horn demonstra a clara separação por tipos de 
solo, evidenciando a existência de espécies seletivas e/ou exclusivas (Figura 1). As áreas 1, 3 e 5, apesar de estarem inseridas na planície costeira, $\mathrm{n}$ o compartilham o tipo de solo arenoso das demais áreas. A rea 1 encontra-se na planície propriamente dita, enquanto as áreas 3 e 5 situam-se em pequenos morros isolados e imersos na planície. Nessas áreas de menor drenagem, onde o solo é mais rico em matéria orgânica e há maior capacidade de armazenamento de água, destaca-se a dominância de espécies comuns da floresta de encosta, como Hyeronima alchorneoides, Cupania oblongifolia, Campomanesia. reitziana e Euterpe edulis; espécies comuns da florestas de planície arenosa, como Tapirira guianensis, Tibouchina pulchra e Jacaranda puberula; além da presença de espécies da restinga regional como Guarea macrophylla, Pera glabrata, Alchornea triplinervia, Syagrus romanzoffiana e Miconia cinnamomifolia (VELOSO; KLEIN, 1961; GUAPYASSÚ, 1994; NEGRELLE, 2006; MELO JÚNIOR; BOERGER, 2015). As áreas 4, 2 e 6 compartilham, além do tipo de solo arenoso, a domin ncia de Richeria grandis, espécie característica de uma associação típica que é encontrada em pequenas depressões do terreno, onde a espécie, em virtude de sua elevada contribuição sociológica, empresta um aspecto fisionômico próprio à vegetação (VELOSO et al., 1961). Outras espécies dominantes dessa associação, como A. triplinervia, Calophyllum brasiliense, Psidium cattleianum, Pera glabrata e Ocotea pulchella, são próprias das formações da restinga regional, enquanto T. guianensis, T. pulchra e $J$. puberula são próprias da floresta da planície arenosa (VELOSO; KLEIN, 1961; GUAPYASSÚ, 1994; NEGRELLE, 2006; MELO JÚNIOR; BOERGER, 2015).

Para efeito de discussão, a Tabela 5 apresenta as espécies indicadoras de diferentes propostas de classificação dos estágios sucessionais da Floresta Ombrófila Densa. Pode ser verificado nessa tabela que a Resolução CONAMA-SC reconhece apenas duas espécies arbóreas indicadoras do estágio médio de regeneração da Floresta Ombrófila Densa, sendo uma (Dodonaea viscosa Jacq.) fortemente associada à restinga, enquanto a outra (Rapanea ferruginea (Ruiz \& Pav.) Mez) é característica de florestas secundárias em regeneração (SIMINSKI; FANTINI, 2004; SIMINSKI et al., 2011). Para o estágio avançado, a resolução reconhece uma série de espécies associadas à floresta de encosta e à restinga, porém ignora aquelas que são dominantes nas planícies arenosas como T. guianensis, T. pulchra, J. puberula e R. grandis (VELOSO; KLEIN, 1961). Apesar de a CONAMA-SC apresentar uma tentativa de listar as espécies indicadoras da Floresta Ombrófila Densa em toda sua abrangência, fica claro que ela não apresenta espécies indicadoras adequadas

TABELA 5: Espécies indicadoras de diferentes propostas de classificação de estágios sucessionais da Floresta Ombrófila Densa.

\begin{tabular}{|c|c|c|}
\hline $\begin{array}{l}\text { Propostas de } \\
\text { classificação }\end{array}$ & $\begin{array}{l}\text { Estágios de } \\
\text { regeneração }\end{array}$ & Espécies indicadoras \\
\hline \multirow[b]{2}{*}{$\begin{array}{l}\text { CONAMA-SC } \\
(04 / 94)\end{array}$} & Médio & Rapanea ferruginea* e Dodonaea viscosa \\
\hline & Avançado & $\begin{array}{l}\text { Miconia cinnamomifolia, Psychotria longipes, Cecropia adenopus, Euterpe edulis, } \\
\text { Schizolobium parahiba, Bathiza meridionalis, Piptadenia gonoacantha, Hieronyma } \\
\text { alchorneoides, Alchornea triplinervia, Nectandra leucothyrsus, Ocotea catharinensis, } \\
\text { Euterpe-edulis, Talauma ovata, Chrysophylum viride e Aspidosperma olivaceum, entre } \\
\text { outras. }\end{array}$ \\
\hline \multirow{2}{*}{$\begin{array}{l}\text { CONAMA-PR } \\
\quad(02 / 94)\end{array}$} & Médio & $\begin{array}{l}\text { Ilex theezans, Piptocarpha } \\
\text { A. angustifolia, Ocotea puberula, Euterpe edulis, Schizolobium parayba, Vochsia } \\
\text { bifalcata, Cedrela fissilis e Tabebuia cassinoides }\end{array}$ \\
\hline & Avançado & $\begin{array}{l}\text { Araucaria angustifolia, Ocotea porosa, Peltophorum dubgium, Tabebuia alba, } \\
\text { Parapiptadenia rigida e Ficus sp. }\end{array}$ \\
\hline
\end{tabular}

*Foi mantido o nome original da espécie indicado na Resolução CONAMA 04/04, na qual atualmente é aceita a nomenclatura nova Myrsine coriacea (Sw.) R.Br. 
para apontar o estágio sucessional de fragmentos das florestas de planície.

Por sua vez, a Resolução CONAMA-PR apresenta uma mistura de espécies da Floresta Ombrófila Densa (e.g.: Schizolobium parahyba (Vell.) Blake), Mista (e.g.: Piptocarpha angustifolia Dusén ex Malme; Araucaria angustifolia (Bertol.) Kuntze 1898) e Estacional (e.g: Parapiptadenia rigida (Benth.) Brenan), dificultando em muito o reconhecimento de espécies indicadoras por meio dessa Resolução. É percebido que essa resolução é, também no aspecto florístico, menos restritiva do que a CONAMA-SC, uma vez que para a Floresta Ombrófila Densa reconhece espécies de clímax regional (e.g.: S. parahyba e E. edulis) (VELOSO; KLEIN, 1957) como indicadoras de fragmentos em estágio médio de regeneração.

Conforme demonstrado por Veloso e Klein et al. (1961), as florestas da planície costeira da região Norte de Santa Catarina apresentam um caráter pioneiro, com um desenvolvimento médio (se comparadas com as florestas de encosta) e com um pequeno número de espécies com altos valores sociológicos. Essas características diferenciam tanto essa formação das áreas de restinga como das áreas da floresta de encosta, porém, a dominância de algumas espécies permeia entre essas três formações. Essa planície é caracterizada por um lento caminhamento sucessional de um est gio mais pioneiro onde espécies dominantes da restinga vão sendo substituídas por espécies da encosta, enquanto outras têm seu desenvolvimento ótimo ainda na planície, imprimindo, ainda que de maneira singela, uma característica singular a essa formação. Sendo assim, poderia ser considerada toda essa formação (Terras Baixas) como uma área de transição entre a restinga e a floresta de encosta, o que implicaria legalmente a utilização da Resolução CONAMA 261/1999 para a classificação dos estágios sucessionais de seus fragmentos.

Esse aspecto é reforçado por estudos recentes como o de Paz (2016), em que o autor, analisando áreas localizadas no litoral centro-norte de Santa Catarina, propõe a utilização de sítios físicos no reconhecimento de macroambientes a fim de se obter uma relação Macroambiente-Fitofisionomia-Normativa legal. $\mathrm{O}$ autor segregou sua rea de estudos em três macroambientes, um vinculado à Restinga, outro não vinculado à Restinga, além de uma área de transição entre os dois macroambientes. Os resultados revelaram a preferência das espécies G. macrophylla e T. guianensis ao macroambiente de transição. Em outro trabalho, Lingner et al. (2013) encontram diferenças significativas entre a composição florística da Floresta Ombrófila Densa localizada em cotas altitudinais abaixo de $30 \mathrm{~m}$ se comparadas com maiores elevações. Os autores, ainda, analisaram as espécies indicadoras para variadas faixas altitudinais do estado de Santa Catarina, em que as espécies indicadoras da porção das Terras Baixas (abaixo dos $30 \mathrm{~m}$ ) foram representadas por muitas semelhantes as desse estudo, com destaque para T. guianensis.

Contudo, se por um lado a CONAMA-PR e a proposta de Siminski et al. (2013) são menos restritivas, a utilização da CONAMA 261/1993 implicaria a classificação em estágio avançado de fragmentos ainda jovens, uma vez que tanto as características qualitativas quanto as quantitativas dessa Resolução seriam facilmente observadas nesses fragmentos. Esse pode ser um dos principais fatores que, aliado à definição de Floresta Ombrófila Densa das Terras Baixas, conforme IBGE (2012), leva à utilização da CONAMA-SC em detrimento da Resolução CONAMA 261/93 nos processos de licenciamento ambiental do litoral norte de Santa Catarina, sobretudo nos municípios de Joinville e Araquari.

Os resultados deste estudo demonstram que há evidente incoerência no texto da Resolução CONAMASC tanto por parte dos parâmetros estruturais da vegetação como das espécies indicadoras de cada estágio sucessional. Essa incoerência denota que os valores dos diferentes parâmetros quantitativos indicam tanto o estágio médio como o estágio avançado, podendo resultar em indicações de estágios sucessionais de menor restrição nos processos de licenciamento ambiental. Já as espécies indicadoras descritas na Resolução não são adequadas para descrever a planície costeira norte do estado de Santa Catarina. Assim, os fragmentos florestais do estado podem estar sendo submetidos a usos de solo incompatíveis com aqueles descritos na Lei 11.428/2006 
(Lei da Mata Atlântica), perdendo o efeito esperado da definição dos estágios sucessionais.

Por fim, enquanto não houver uma revisão das políticas públicas que versam sobre o tema, além das incoerências mencionadas no texto, as áreas de transição entre os ambientes de Restinga e da Floresta de Encosta (potencialmente as áreas desse estudo) podem se fazer valer da utilização da Resolução incorreta e/ ou incompleta na indicação do estágio sucessional, trazendo sérios prejuízos para o a conservação dos seus remanescentes florestais do estado.

\section{Agradecimentos}

À CAPES, pelo incentivo à pesquisa e ao biólogo Flavio Beilke, pelo auxílio nos trabalhos de campo e na identificação das espécies.

\section{Referências}

BARROSO, G. M. Sistemática de Angiospermas do Brasil. Viçosa: Universidade Federal de Viçosa, 1986. 386 p.

BLUM, C. T.; RODERJAN, C. V. Espécies indicadoras em um gradiente da Floresta Ombrófila Densa na Serra da Prata, Paraná, Brasil. Revista Brasileira de Biociências, Porto Alegre, v. 5. n. 2, p. 873-875, 2007

CHAO, A.; CHAZDON, R. L.; COLWELL, R. K.; SHEN, T. Abundance-based similarity indices and their estimation when there are unseen species in samples. Biometrics, Washington, v. 62, n. 2, p. 361-371, 2006.

CLARK, D. B., PALMER, M. W.; CLARK, D. A. Edaphic factors and the landscape-scale distribuitions of tropical rain-forest trees. Ecology, New York, v. 80, n. 8, p. 2662-2675, 1999.

CONAMA - CONSELHO NACIONAL DO MEIO AMBIENTE. Resolução no 10, de 01 de outubro de 1993, 1993.

CONAMA - CONSELHO NACIONAL DO MEIO AMBIENTE. Resolução no 2, de 18 de março de 1994, 1994a.

CONAMA - CONSELHO NACIONAL DO MEIO AMBIENTE. Resolução no 4, de 04 de maio de 1994, 1994 b.

CONAMA - CONSELHO NACIONAL DO MEIO AMBIENTE. Resolução no 261, de 30 de junho de 1999, 1999.

CONAMA - CONSELHO NACIONAL DO MEIO AMBIENTE. Resolução no 388, de 23 de fevereiro de 2007, 2007.

DEAN, W. A ferro e fogo: a história e a devastação da Mata Atlântica brasileira. São Paulo: Companhia das Letras, 1996. 484 p. EPAGRI - EMPRESA DE PESQUISA AGROPECUÁRIA E DE EXTENSÃO RURAL DE SANTA CATARINA S.A. Mapa de solos Unidade de Planejamento Regional Litoral Norte Catarinense UPR 6, 2002.
FINEGAN, B. Pattern and process in neotropical secondary rain forests: the first 100 years of succession. Trends in Ecology \& Evolution, London, v. 11, n. 3, p. 119-124, 1996.

FINEGAN, B.; DELGADO, D. Structural and floristic heterogeneity in a 30-year-old Costa Rican rain forest restored on pasture through natural secondary succession. Restoration Ecology, Crawley, v. 8, n. 4, p. 380-393, 2000.

GAIO, A. Lei da mata atlântica comentada. S o Paulo: Almedina, 2014. 232 p.

GUAPYASSÚ, M. S. Caracterização fitossociológica de três fases sucessionais de uma Floresta Ombrófila Densa Submontana - Morretes - Paraná. 1994. 150 f. Dissertação (Mestrado em Engenharia Florestal) - Universidade Federal do Paraná, Curitiba. 1994.

HORN-FILHO, N. O. Setorização da Província Costeira de Santa Catarina em base aos aspectos geológicos, geomorfológicos e geográficos. Departamento de Geociências. Geosul, Florianópolis, v. 18, n. 35, p.71-98, 2003.

HORN-FILHO, N. O. ; SCHMIDT, A. D.; BENEDET, C.; NEVES, J.; PIMENTA, L. H. F.; PAQUETTE, M.; ALENCAR, R.; SILVA, W. B.; VILLELA, E.; GENOVEZ, R.; SANTOS, C. G. Estudo Geológico dos depósitos clásticos quaternários superficiais da Planície Costeira de Santa Catarina, Brasil. Gravel, Porto Alegre, v. 12, n. 1, p. 41-107, 2014.

IBGE - INSTITUTO BRASILEIRO DE GEOGRAFIA E ESTATÍSTICA. Manual técnico da vegetação brasileira. 2. ed. Rio de Janeiro: IBGE, 2012. 275 p.

JASTER, C. B. A estrutura como indicadora do nível de desenvolvimento sucessional de comunidades arbóreas da restinga - uma proposta metodológica. 2002. 221 f. Tese (Doutorado em Ciências Florestais) - Universidade Federal do Paraná, Curitiba. 2002.

LIEBSCH, D.; GOLDENBERG, R.; MARQUES, M. C. M. Florística e estrutura de comunidades vegetais em uma cronoseqüência de Floresta Atlântica no estado do Paraná, Brasil. Acta Botanica Brasilica, Belo Horizonte, v. 21, n. 4, p. 983-992, 2007.

LINGNER, D. V.; SEVEGNANI, L.; GASPER, A. L.; UHLMANN, A.; VIBRANS, A. C. Grupos florísticos estruturais da Floresta Ombrófila Densa em Santa Catarina. In: VIBRANS, A. C.; SEVEGNANI, L.; GASPER, A. L.; LINGNER, D. V (Ed.). Inventário florístico florestal de Santa Catarina, Vol IV, Floresta Ombrófila Densa. Blumenau: Edifurb, 2013. p. 143-157.

MARCHIORI, J. N. C. Dendrologia das angiospermas: das bixáceas às rosáceas. Santa Maria: UFSM, 2000. 240 p.

MARCHIORI, J. N. C. Dendrologia das Angiospermas: leguminosas. 2. ed. Santa Maria: UFSM, 2007. 200 p.

MARQUES, M. C. M.; SWAINE, M. D.; LIEBSCH, D. Diversity distribution and floristic differentiation of the coastal lowland vegetation: implications for the conservation of the Brazilian Atlantic Forest. Biodiversity and Conservation, New York, v. 20, n. 1, p. 153-168, 2010.

MEIRA, J. C. Direito Ambiental. Informativo Jurídico da Biblioteca Ministro Oscar Saraiva, Barsília, v. 19, n. 1, p. 11-23, 2008.

MELO JÚNIOR, J. C. F.; BOERGER, M. R. T. Riqueza, estrutura e interações edáficas em um gradiente de restinga do Parque Estadual 
do Acaraí, estado de Santa Catarina, Brasil. Hoehnea, São Paulo, v. 42, n. 2, p. 207-232, 2015.

MUELLER-DOMBOIS, D.; ELLENBERG, H. Aims and methods of vegetation ecology. New York: The Blackburn Press, 2003. $547 \mathrm{p}$.

NEGRELLE, R. R. B. Composição florística e estrutura vertical de um trecho de Floresta Ombrófila Densa de Planície Quaternária. Hoehnea, São Paulo, v. 33, n. 3, p. 261-289, 2006.

PANDOLFO, C.; PEREIRA, E. S.; SILVA JÚNIOR, V. P.; THOMÉ, V. M. R.; PEDRA, E. R.; HAMMES, L. A.; GREGOLIN, G.; TRENTINI, É. C.; VIECILI, F. L.; ANDRIOLLI, Z. M.; VIEIRA, V. F.; MASSIGNAN, A. M. Atlas climatológico do estado de Santa Catarina. Florianópolis: Epagri, 2002. CD-ROM.

PAZ, D. F. Enquadramento legal da vegetação do litoral CentroNorte de Santa Catarina. 2016. 223 f. Dissertação (Mestrado em Perícias Criminais Ambientais) - Universidade Federal de Santa Catarina, Florianópolis. 2016.

REFLORA. Herbário virtual. 2016. Disponível em: $<$ http://www. herbariovirtualreflora.jbrj.gov.br/reflora/herbarioVirtual/>. Acesso em: 12 jul. 2016.

RODERJAN, C. V.; GALVÃO, F.; KUNIOSHI, Y. S.; HATSCHBACH, G. G. As unidades fitogeográficas do estado do Paraná, Brasil. Ciência \& Ambiente, Santa Maria, v. 24, p. 75-92, 2002.

RUSCHEL, A. R.; MANTOVANI, M.; REIS, M. S.; NODARI, R. O. Caracterização e dinâmica de duas fases sucessionais em floresta secundária da mata atlântica. Revista Árvore, Viçosa, v. 33, n. 1, p. 101-115, 2009.

SEVEGNANI, L.; LAPS, R. R.; SCHOROEDER, E. A vertente atlântica. In: SEVEGNANI, L.; SCHOROEDER, E. (Ed.). Biodiversidade catarinense: características, potencialidades, ameaças. Blumenau: Edifurb, 2013. p. 93-133.

SILVA, V. G. Mata Atlântica e a Legislação de Regência. Revista de Direito Ambiental, Caxias do Sul, v. 4, n. 15, p. 88-93, 1999.

SIMINSKI, A.; FANTINI, A. C. Classificação da Mata Atlântica do litoral catarinense em estádios sucessionais: Ajustando a lei ao ecossistema. Floresta e Ambiente, Seropédica, v. 11, n. 2, p. 20 25, 2004.

SIMINSKI, A.; FANTINI, A. C. A Mata Atlântica cede lugar a outros usos da terra em Santa Catarina, Brasil. Biotemas, Florianópolis, v. 23 , n. 2, p. 51-59, 2010.
SIMINSKI, A.; FANTINI, A. C.; GURIES, R. P.; RUSCHEL, A. R.; REIS, M. S. Secondary forest succession in the Mata Atlantica, Brazil: floristic and phytosociological trends. International Scholarly Research Notices Ecology, Cairo, Article ID 759893 , p. 1-19, 2011.

SIMINSKI, A.; FANTINI, A. C.; REIS, M. S. Classificação da vegetação secundária em estágios de regeneração da Mata Atlântica em Santa Catarina. Ciência Florestal, Santa Maria, v. 23, n. 3, p. 369-378, 2013.

SOBRAL, M. A família "Myrtaceae" no Rio Grande do Sul. S o Leopoldo: Unisinos, 2003. 216 p.

SOUZA, V. C.; LORENZI, H. Botânica sistemática: guia ilustrado para identificação das famílias de Angiospermas da flora brasileira, baseado em APG II. Nova Odessa: Instituto Plantarum, 2005. $604 \mathrm{p}$.

SPERZEL, F. F. Análise dos parâmetros para o reconhecimento de estágio sucessional da Floresta Ombrófila Desa. Estudo de caso: Floresta Aluvial no Parque Raimundo Malta, Balneário Camboriú, SC. 2016. 86 f. Dissertação (Mestrado em Ciência e Tecnologia Ambiental) - Universidade do Vale do Itajaí, Itajaí. 2016.

TABARELLI, M.; MANTOVANI, W. A regeneração de uma floresta tropical montana após corte e queima (São Paulo - Brasil). Revista Brasileira de Biologia, São Carlos, v. 59, n. 2, p. 239-250, 1999.

VELOSO, H. P.; KLEIN, R. M. As comunidades e associações vegetais da mata pluvial do sul do Brasil. I. As associações do município de Brusque, estado de Santa Catarina. Sellowia, Itajaí, v. 13, p. 81-235, 1957.

VELOSO, H. P.; KLEIN, R. M. As comunidades e associações vegetais da mata pluvial do sul do Brasil. III. As associações das Planícies costeiras do quaternário, situadas entre o Rio Itapocu (estado de Santa Catarina) e a Baia de Paranaguá (estado do Paraná). Sellowia, Itajaí, v. 13, p. 205-260, 1961.

VELOSO, H. P.; RANGEL-FILHO, A. L. R.; LIMA, J. C. A. Classificação da vegetação brasileira adaptada a um sistema universal. Rio de Janeiro: IBGE, Departamento de Recursos Naturais e Estudos Ambientais, 1991. 124 p.

WAINER, A. H. Legislação ambiental brasileira-evolução histórica do direito ambiental. Revista de Direito Ambiental, Caxias do Sul, v. 30, n. 118, p. 191-206, 1993.

WOLDA, H. Diversity, diversity indices and tropical cockroaches. Oecologia, Heidelberg, v. 58, n. 3, p. 290-298, 1983. 